\title{
EXAMINING THE OPINION OF EXPERTS IN JUDO ON THE NEED FOR A TRAINING METHODOLOGY FOR CHILDREN AGED 7 TO 10
}

\author{
A. Yaneva*, V. Lukanova \\ Department of Sport, Individual sports and recreation, Sofia University "St. Kliment Ohridski”, \\ Sofia, Bulgaria
}

\begin{abstract}
Using the survey method, a study of Judo coach opinion in Bulgaria on the need to introduce a Judo training methodology for different ages, particularly for children aged 7 to 10, was conducted. Several statistical methods have been used. The results of the study were processed in percentage by the Excel program and presented graphically. The study shows that most judo specialists are convinced that it is necessary to develop a teaching and training methodology for all ages and especially for children. Experts also give their opinion on the important aspects of the training that should be included in the training methodology.
\end{abstract}

Key words: judo, children aged 7 to 10 , training methodology

\section{INTRODUCTION}

Although episodically, in the last few years Bulgarian Judo has again appeared on the international stage. The successes of several contestants, such as Ivaylo Ivanov, Yanislav Gerchev, Ivelina Ilieva, Betina Temelkova and others, show that the development of judo in Bulgaria has the potential. This potential should be sought in preparation from an early age, such as in the pediatric age group.

For the practical realization of the preparedness, both the technical and the general training of the judist, such as the physical, psychological, theoretical, emotional and other aspects of personality development, are essential. No part of Judoka's preparation should be ignored.

Judo is characterized by its dynamics, the variability of the situations, the variation, the flexible application of the techniques of attack, the defense, the control both in the stand (tachi wadza) and in the ground - low fight (ne waza). The dynamics of the racing match

\footnotetext{
*Correspondence to: Anzhelina Georgieva Yaneva, Department of Sport, Individual sports and recreation, Sofia University "St. Kliment

Ohridski", address: bul. "Tsar Osvoboditel" 15, 1504 Sofia, Bulgaria, E-mail: anji@abv.bg, Phone: $+359888434880$
}

require the judo competitor to master the necessary amount of techniques, use them in the situations (not to miss the moment) and at the same time be prepared very well physically.

The study, consolidation and improvement of the large number of judo techniques in a stand and groundwork require the development of physical qualities such as endurance, strength, speed, flexibility, agility, etc. that provide practical activity through purposeful physical actions to overcome and overcome different extreme situations in which each of the contestants strives to gain victory in the active opposition of the other. (1)

They should not ignore the other sides in the preparation of Judoka as psychophysical training. It is related to the improvement of the human personality and helps to improve not only the health but also the successful overcoming of stressful situations and life crises. "Good psychological training gained from sport can be a key factor in the success of the personality in all aspects of life." (2).

The overall preparation for judo activities is related to the improvement of the human person, not only to improve health, but also to successfully overcome the stressful situations and life crises, as well as the manifestation of 
the personality and the realization of the goals set in the dynamic conditions of the judo environment. On this basis, the individual builds a Judo-specific intellect that can be used in critical (extreme) situations. (3)

Generalized Judo forms not only the physical and mental individual but also builds lasting moral resistances that influence the formation of the personality.

The basis on which judo training is built are the main didactic principles: consciousness, activity, visual, systemic, consistency, accessibility, and durability, with a special place for the method of exercise and repetition. This is the surest way to establish and reinforce the necessary knowledge and skills.

The goal in the initial stage of preparation is not to build competitors but to lay the foundations for the growth of focused healthy, motivated and motivating people who can concentrate to demand from oneself and others the observance of ethical rules and norms of behavior.

The competitor in judo takes years to develop. The first official judo races for children begin at the age of 9. As children begin to engage in judo from 7 to 8 years of age, even younger, they are actually in a preparatory group. This is a very appropriate time when children can prepare without having to hurry in their realization and chase high results. In this period, they can gain more knowledge and skills to benefit in the next stage of their preparation and entry into the sporting competition stage.

Although in the preparatory stage of training, there is no exact boundary between training and training. There is no telling moment in which the training ends and the training begins. Even with the first steps of judo learning, the training begins, which must be tailored to the specifics of the motor system and its management in adolescents. (4). From the didactic point of view and in accordance with the main tasks that are being solved, the two sides of this multifaceted and complex process are distinguished.

The main task that is allowed in the training is the all-round construction of the personality of the Judith. Unlike most sports disciplines (athletics, gymnastics, heavy athletics, etc.), judo sports implies a much more complex development of motor skills and their functional interdependence with sporting technical skills. (5)

The above, as well as the practice, show that, in order to be successful, a Judoka must have a wide command of judo's technique and tactics, have a broad and solid foundation of welldeveloped physical and muscular qualities, be mentally resilient and have the theoretical knowledge, to be shaped as a person of high moral and volitional qualities.

This can be achieved by methodically substantiated years of preparation by preparing Judoka starting from early childhood. Training at an early age, when from Judoka not want excellence in competition, will allow sufficient time to accumulate knowledge and skills to build as a competitor in judo.

\section{PURPOSE}

The purpose of this study is to reveal the need to create and implement a judo training and instructional methodology for children aged 7 to 10 .

The tasks that result from the goal are:

1. Investigate the literary sources on the problem.

2. Conducting a survey with judo specialists from the current coaches and instructors in the Republic of Bulgaria.

3. Analysis and presentation of the results obtained.

\section{METHODS}

In the development of the survey and the implementation of the survey, the following tools were applied: survey method - survey, alternative analysis (the relative share of the response was calculated in terms of the total number of respondents), graphical analysis and comparative analysis of the relative shares.

\section{RESULTS AND DISCUSSION}

The survey was conducted anonymously and online (https://app.crowdsignal.com/surveys/) in the period April 5-10, 2019. Questions, just one of which is open, making the poll easy to fill and does not take long. The average time to complete the survey took 3 minutes and 37 seconds for the respondents. The fastest poll is completed for $1 \mathrm{~min}$ and $20 \mathrm{sec}$, and the slowest for $10 \mathrm{~min}$ and $55 \mathrm{sec}$.

The survey was completed by 36 judo specialists, $88 \%$ of whom are judo coaches, $6 \%$ judo and sambo. (Figure 1) By age, the distribution is in favor of the age between 46 and 60 (over 50\%), which explains the higher 
percentage of coaches and coaches. (Figures 2 and 3) The distribution by gender is in favor of men $(61 \%)$, as is the distribution of working coaches in Bulgaria to the Bulgarian Judo Federation. (Figure 4)

Figure 5 graphically represent the percentage of participants of the age group data that specialists conduct training. The distribution of responses shows that most coaches (nearly $80 \%$ ) work with groups in the age range of 7 to 10 years, which determines the respondents as judo specialists, especially for this age. (Figure 5)

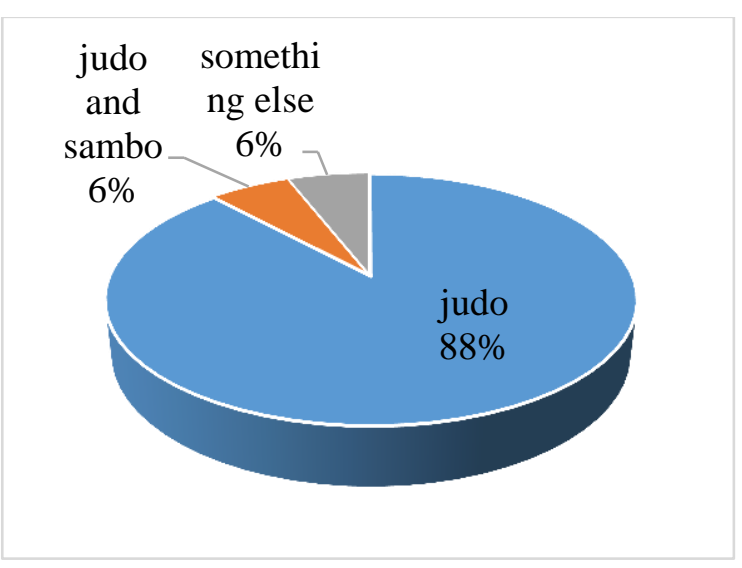

Figure 1. Specialist on ...

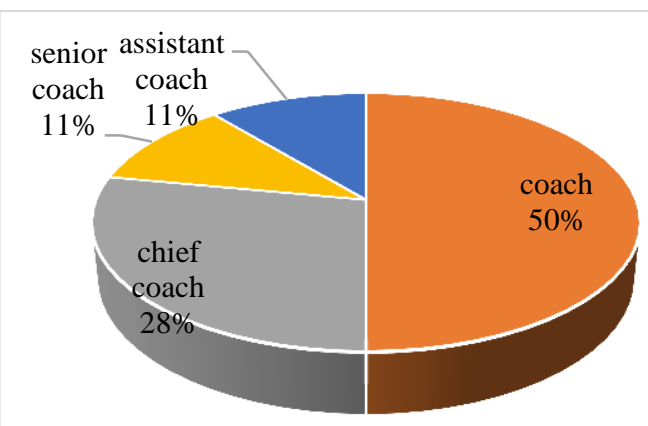

Figure 2. Are you (coach, instructor)?

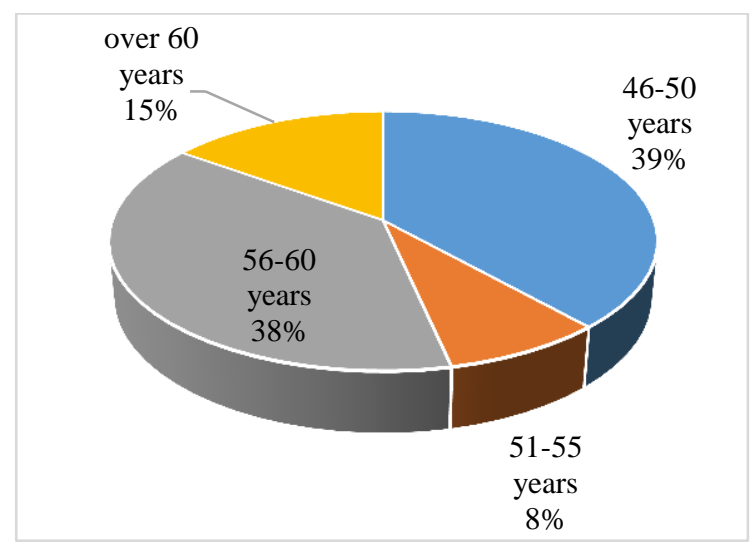

Figure 3. Age

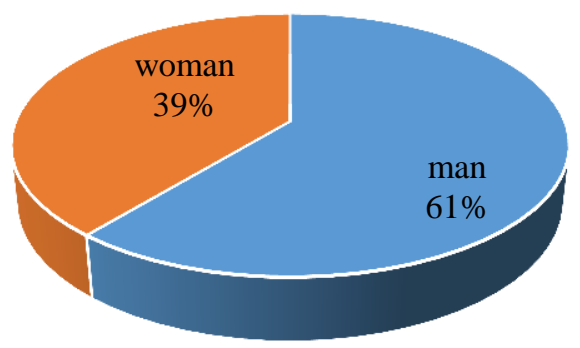

Figure 4. Gender

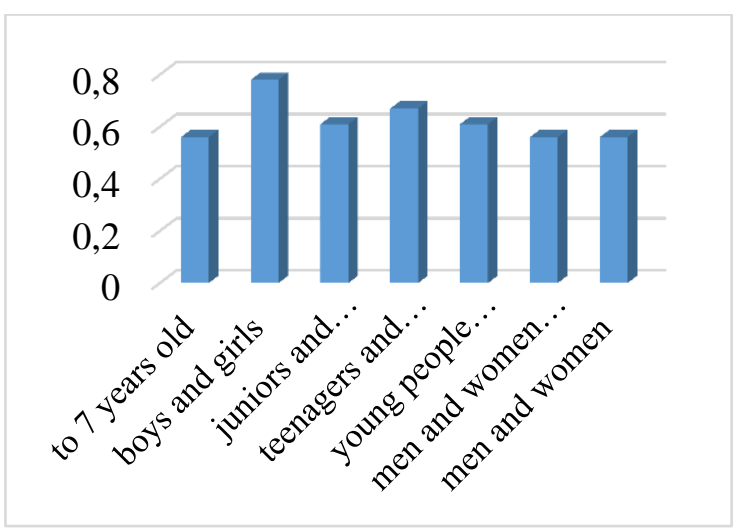

Figure 5. Age groups

The following question is the basis of this study, namely: "Do you think there is a need to develop a united form teaching methodology for the age?". Figure 6 clearly shows that there is a need to develop a judo teaching methodology for all ages, but most of the respondents $(83 \%)$ are firmly convinced that such a methodology is most needed for the age range for children up to 7 years old and for boys and girls. (Figure 6)

The largest number of coaches (66\%) who believe that the optimal number of activities for this age group is 3 times $16 \%$ state four times, but it is noteworthy that nobody has pointed answers "one" or "two times ". This is due to the fact that judo sport is related to the absorption of complex coordination movements, which should be learned not only in detail but also lasting. (Figure 7)

The answers to the question, "What physical qualities must mostly develop in boys and girls?" Make the impression that specialists point out that the physical qualities of speed, agility and flexibility must be developed as a matter of priority, which qualities should be developed according to the age specifics for this group of children, according to various specialists in the theory and methodology of physical education and sport. (Figure 8) 


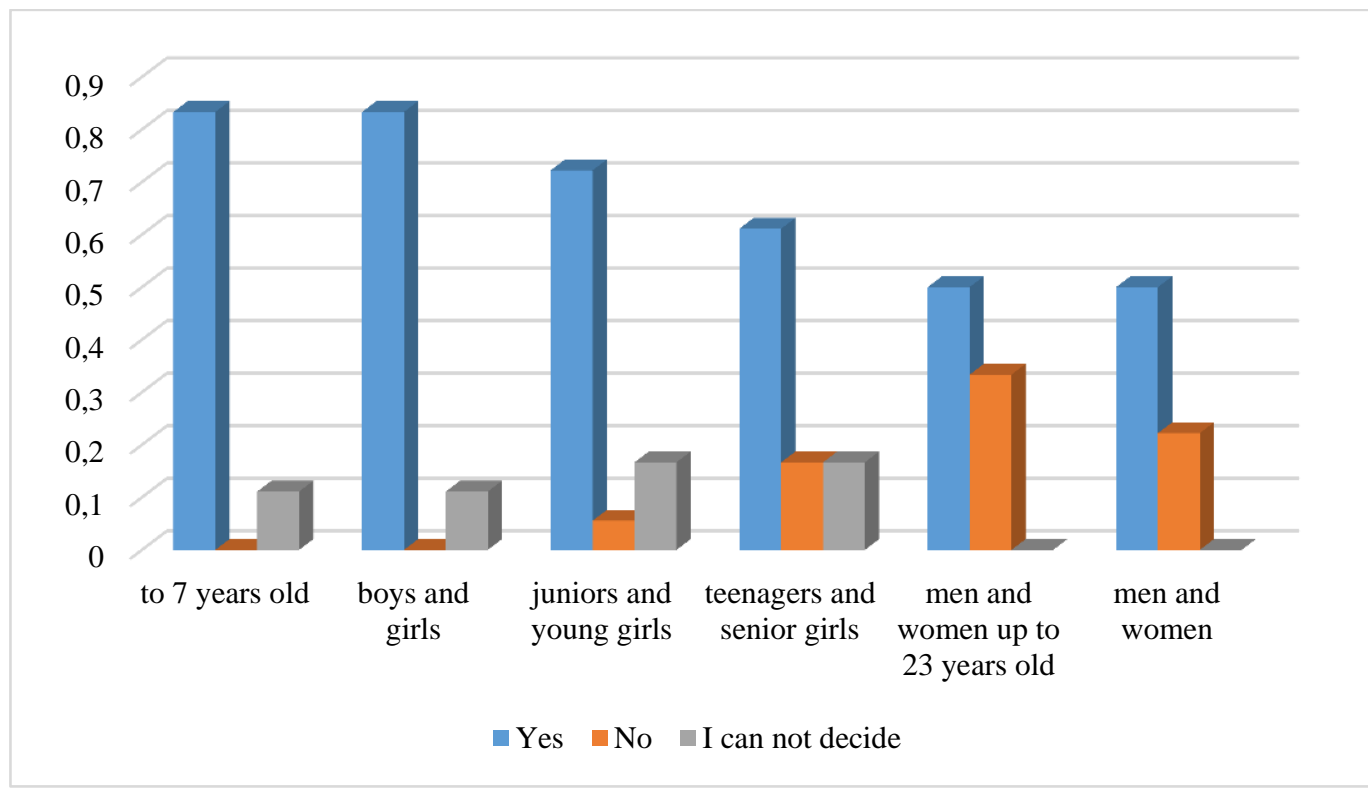

Figure 6. Need to develop a uniform training methodology

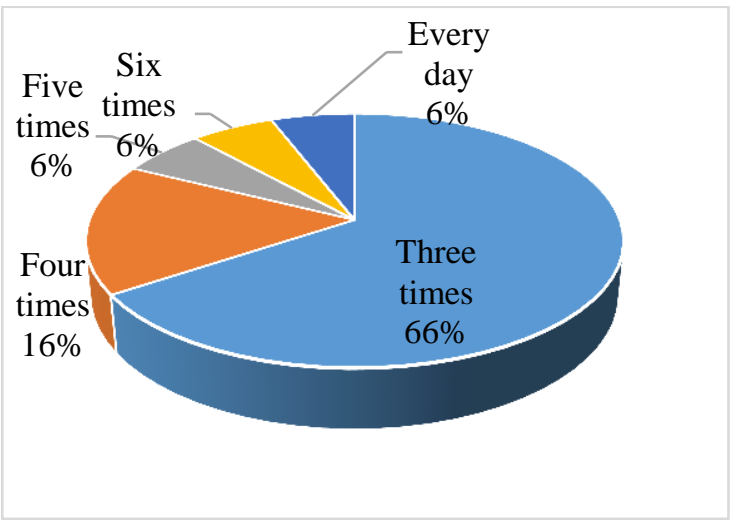

Figure 7. Weekly Load

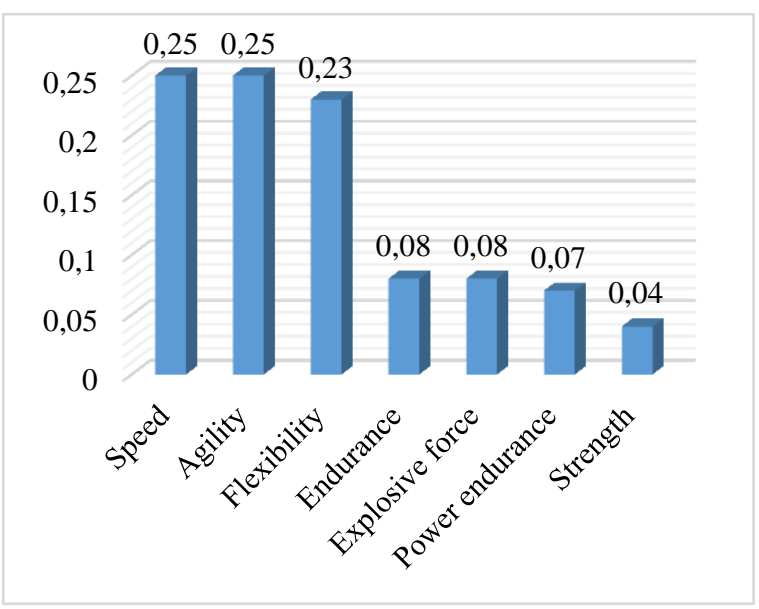

Figure 8. Development of physical qualities

Experts believe that in this age group, the stand-up techniques required by boys and girls are from the Ashi Waza group (foot techniques) - 39\% and the Koshi Waza (techniques with pelvis) - 33\%. There is a small percentage of professionals $(22 \%)$ who believe that children should also be trained in techniques of $\mathrm{Te}$ Waza group (hand techniques) $-22 \%$. It is a good idea to learn that it is not necessary to learn techniques from the group of Sutemi Waza (self-sacrificing technician) - 2\%. (Figure 9)

To the question, "What, in your opinion, should be the preparation in $\mathrm{Ne}$ Waza (ground floor) for boys and girls? What more to pay attention to? ", More than half of the respondents $(64 \%)$ say that the detention techniques as well as the detention re treatments should be given the most attention. Half of the experts believe that transitions to retention from different starting positions should be studied, and 30\% are transitions from stand to ground. (Figure 10)

In conclusion, the following can be summarized:

Judo experts are of the opinion that it is necessary to develop and implement a judo training and judging methodology for children aged 7 to 10 . The methodology should cover all aspects of Judi's preparation:

- Priority development of physical qualities speed, flexibility and agility;

- Learning the techniques of the group of Ashi and Koshi waza (foot and pelvic techniques) that build a sense of distance, moment of attack and protection, orientation in space, and development of agility and flexibility in the judoka.

The results obtained give reason to conclude that the conducted research reveals opportunities for innovations in the training 
YANEVA A., et al.

and preparation of judges in a preparatory group.

Experimenting and introducing the proposals mentioned in the survey would contribute to the development of the training methodology and would unify the forms of preparation in this age group.

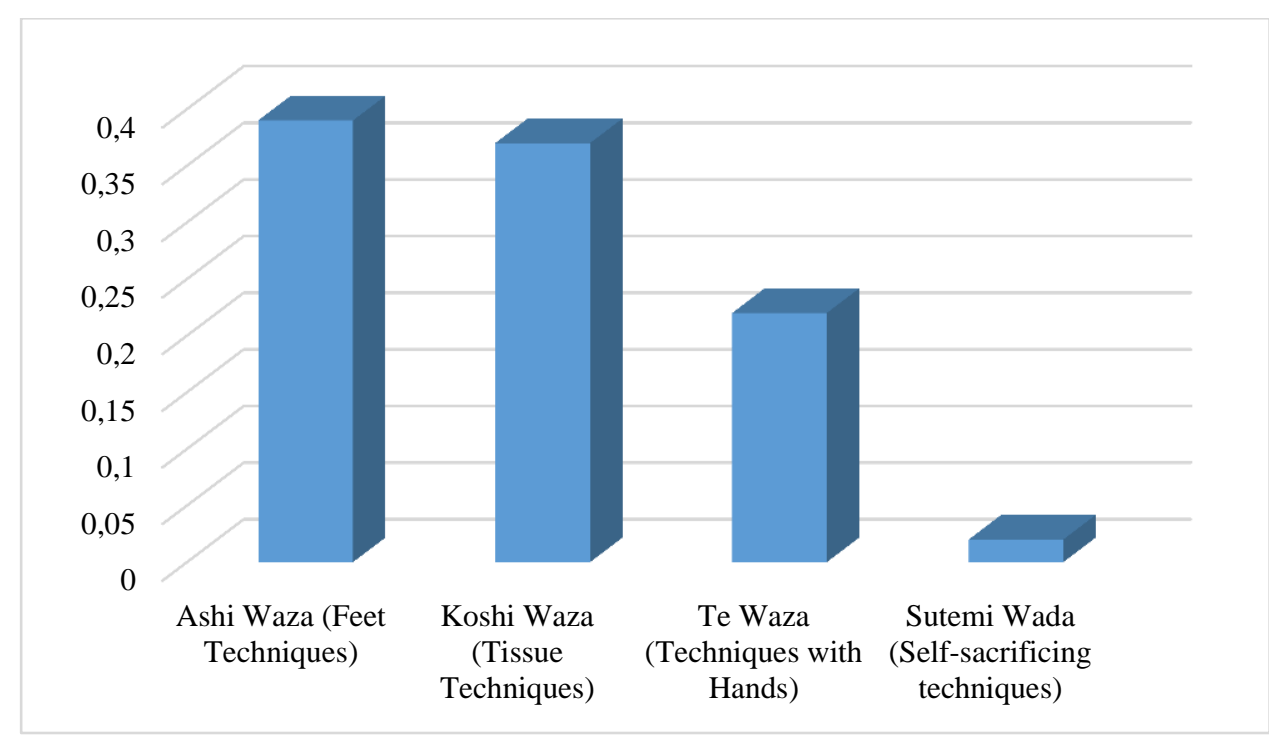

Figure 9. Techniques in Tachi waza (stand)

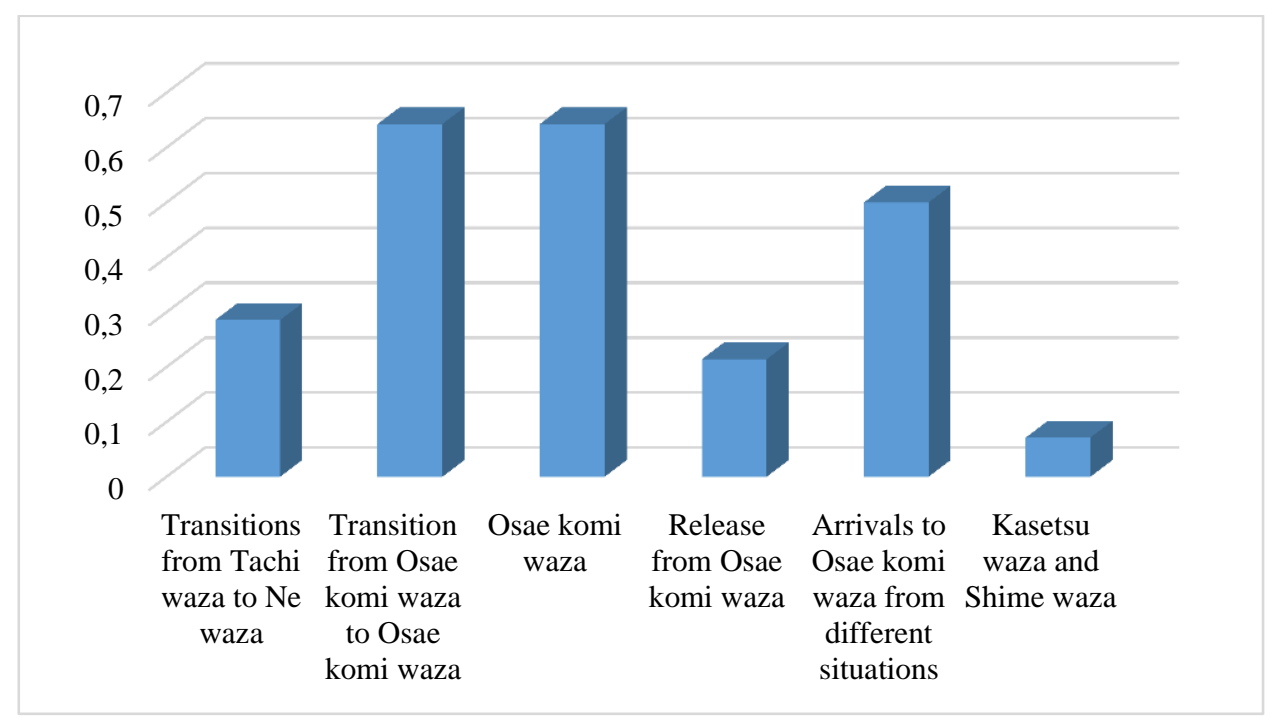

Figure 10. Techniques in Ne waza (ground/parter)

\section{ACKNOWLEDGMENTS}

This article is published with the financial support of project № 80-10-62 / 10.04.2019, according to Ordinance No. 9 of the State Budget of the Republic of Bulgaria.

\section{REFERENCES}

1. Prokopov, E., Judo - philosophy, history, structure, essence. University press „St. Kliment Okhridski“", Sofia, 2005.

2. Peltekova, I. Sports basketball training for student teams. University press „St.
Kliment Okhridski",Sofia, ISBN 978-95407-3680-8, S., 2014.

3. Stoyanova, E., Dispute as a sport. The International Scientific Conference "Modern trends of physical education and sport", 2018.

4. Dimitrova N. Classification structure of motor action in judo sport for children, Sport and Science, S., 2002.

5. Dimitrova, N. On the realization efficiency of sports and technical mastery in Judo, Sports and Science, 2, Sofia, 2012. 